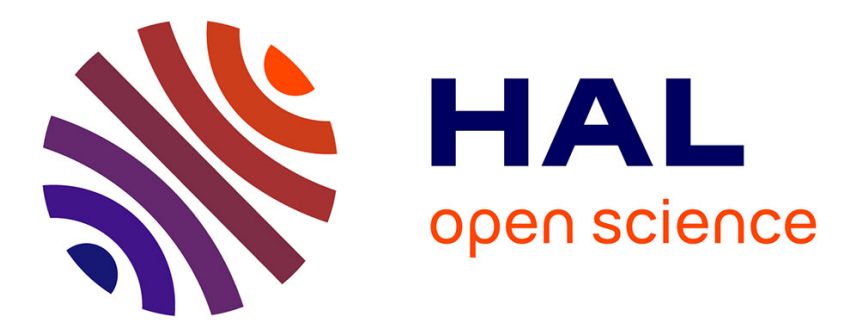

\title{
Room temperature structure development for high-current applications
}

\author{
R. Ferdinand
}

\section{To cite this version:}

R. Ferdinand. Room temperature structure development for high-current applications. 22nd Particle Accelerator Conference 07 (PAC'07), Jun 2007, Albuquerque, United States. pp.2564-2568, 10.1109/PAC.2007.4440726 . in2p3-00169245

HAL Id: in2p3-00169245

https://hal.in2p3.fr/in2p3-00169245

Submitted on 3 Sep 2007

HAL is a multi-disciplinary open access archive for the deposit and dissemination of scientific research documents, whether they are published or not. The documents may come from teaching and research institutions in France or abroad, or from public or private research centers.
L'archive ouverte pluridisciplinaire HAL, est destinée au dépôt et à la diffusion de documents scientifiques de niveau recherche, publiés ou non, émanant des établissements d'enseignement et de recherche français ou étrangers, des laboratoires publics ou privés. 


\title{
ROOM TEMPERATURE STRUCTURE DEVELOPMENT FOR HIGH-CURRENT APPLICATIONS
}

\author{
R. Ferdinand, GANIL, France
}

\section{Abstract}

Many new high-current accelerators use both roomtemperature and superconducting structures. While it is clear that a low-beam-current, high-duty-cycle accelerator should use superconducting cavities, for high-current (CW) applications room temperature structures are still preferred. This mainly depends on the accelerator constraints and objectives. The paper reviews the new choices made world-wide.

\section{INTRODUCTION}

Two major trends of the present accelerator development exist: towards the highest beam energy or towards the highest beam power. Many new projects have arisen from the latter goal. In ion accelerators, higher power allows a significant increase in the production of secondary particles such as kaons, neutrons, muons, neutrinos and radioactive beams. The applications of such machines are: material and life sciences, acceleratordriven waste transmutation, irradiation tools to test and develop new materials, radioactive isotope beams, and nuclear and particle physics.

The major expectations for the experiments are:

- Condensed matter: $\approx 10-100$ times higher flux than produced by the best research reactors

- Radioactive beams: $\approx 10^{15}$ fission/s which represents a gain of up to $10^{2}$ in flux (or equivalent exoticity) in comparison with projects under construction

- Accelerator Driven Transmutation: $100 \mathrm{MWth}$ for a sub-critical system $\left(\mathrm{k}_{\text {eff }} \approx 0.95\right)$ with a $5 \mathrm{MW}$ proton beam

- Irradiation tool: $\approx 10^{15} \mathrm{n} \cdot \mathrm{cm}^{-2} \cdot \mathrm{s}^{-1}$ and some ten displacements per atom (dpa) per year

- Neutrinos: $\approx 10^{21}$ neutrinos (of all types) per year, orders of magnitude higher than today's SPS production.

Cyclotrons will not be discussed in this paper, despite the success of the Paul Scherrer Institute (PSI) and their Swiss Spallation Neutron Source (SINQ). We will focus on linacs. A non-exhaustive list of such machines (running or projects) is indicated below $[1,2,3,4]$. They are followed by 3 code letters: (i) $\mathrm{P}, \mathrm{LP}$ or $\mathrm{CW}$, designating Pulsed, Long Pulse if $\mathrm{df}>10 \%$, or a CW machine; (ii) HI for intensity over $15 \mathrm{~mA}$ and VHI over $100 \mathrm{~mA}$, and (iii) the status Pr for project, $\mathrm{C}$ for under construction or commissioning and $\mathrm{R}$ for a running accelerator.

- Multipurpose projects: J-Parc -Japan $-P / H I / C$, KOMAC-PEFP - Korea - CW-P/HI/C, LANSCE $U S-L P / H I / R$

- Neutron Spallation sources (SNS -US - P/HI/R, CSNS - China - P/HI/C, ESS - Europe -P/HI/P, ISIS

\section{- $U K-P / H I / R$}

- Irradiation tools (IFMIF, IFMIF-EVEDA Europe/Japan - CW/VHI/Pr-C)

- Muon and neutrino production (LINAC4-SPL Swiss$P-L P / H I / P$

- RIB (SPIRAL 2 - France - CW/C, Eurisol - Europe $C W / P, \mathrm{SPES}$ - Italy - CW/P, SARAF - Israel $C W / C$, RIA now AEBL $-U S C W /$

- ADS (TRASCO - Italy CW/HI/P, EUROTRANS Europe CW/P, ADS - China - P/HI/C

In the past, high-intensity linac designs were also done for tritium production (APT in US, TRISPAL in France) requiring both $\mathrm{CW}$ mode and high to very high proton beam current.

For all machines the major challenge is in the lowenergy part, were the beam quality is defined, leading to possible losses in the high-energy part of the accelerator then activation preventing hands-on maintenance. This is also the place where the choice of structure is less obvious. $R \& D$ has to be carried out with prototypes and testing.

This paper reviews the constraints on designing such machines, the choices made world-wide, and the difficult alternative between room-temperature structure and superconducting (SC) possibilities.

\section{CONSTRAINTS ON CW HIGH POWER DESIGNS}

A typical linac design consists of three main parts: a front end based on ion sources and an RFQ, intermediatevelocity structures which accelerate the beam from the RFQ output to about $150 \mathrm{MeV}$ proton ( $\beta \approx 0.1$ to 0.5 ), and the high velocity structures - often superconducting cavities in recent accelerator design.

In the case of high-power CW machines, the two major constraints for the room temperature cavities are the beam current handling and... the high-duty-factor! The first implies constraints through the beam dynamics with a strong focalisation. The second - starting above $10 \% \mathrm{DF}$ - gives rise to difficulties in engineering, cooling and stabilisation of the cavities in operation. They usually have to deal with power deposition as high as 20$50 \mathrm{~W} / \mathrm{cm}^{2}$ in cavities, with localized points up to 150 $250 \mathrm{~W} / \mathrm{cm}^{2}$. High power accelerators generally requires very tight tolerances, which are difficult to maintain with $1 \mathrm{MW}$ of RF power dissipated in a cavity. The heating may be useful for on-line cavity tuning, the frequency resonance error being usually controlled through the structure temperature. In some cases, the tuning of high duty factor cavities becomes difficult during commissioning at low power.

A great challenge in designing such accelerators is to 
minimize the activation, minimize the cost and maximize the availability.

There is generally no unique solution to a particular project. Different approaches can be used, and the choice between SC and room temperature structures already exists for all the energies range, including RFQ's. The optimum design of an accelerator depends upon its detailed specifications. But the specifications for intensity and energy are still insufficient for optimizing the design. Other important factors like the time structure, emittance of the beam, reliability goals and versatility of the delivered beam (energy, beam current or particle type flexibilities) are fundamental [5].

If we focus on the intermediate part of the machines, one can observe that most of the choices that were made world-wide are related to the knowledge and experience of the team in charge of the accelerator. Few projects accept major risks in the designs which can be costly and the steering committees are reluctant to risk money. Teams use the "well known" principle, and there are no reasons to change this. Small progresses are made at each new project.

The RAMI goal is very difficult to achieve. To reach a linac availability of $95 \%$, the availability of the RF system, for example, must be of the order of $97.5 \%$. Redundancy is obviously needed but organization of the RF distribution to avoid beam interruptions longer than $100 \mathrm{~ms}$ is not obvious, especially for big roomtemperature cavities. Huge RF sources allow capital cost savings, but become a clear weakness of the system in case of failure.

\section{SC OPTIONS}

The intermediate-velocity structures are usually normal-conducting drift-tube linac structures (DTL, SDTL, CCDTL). However, superconducting structures, such as spoke-type, re-entrant, QWR or HWR resonators are being contemplated, especially for CW beams. Almost all machines are today superconducting in their highenergy part, so a paper on room-temperature cavities has to start by justifying the decision against an SC machine.

\section{The Move toward SC Machines}

The concept of SC machine was developed for $\beta=1$ cavities for an electron linac and then extended to proton and ion beams, and then progressively towards lower velocity beams.

In low-beta linacs, SC arrived 20 years ago in $\mathrm{CW}$ design, but for low beam current (i.e. negligible beam loading). The choice of SC cavities became obvious for the RF saving and because of low reliability constraints. Low beam current means low losses. With high beam current, transmission, reliability and maintainability become issues. Today, experience world-wide and progress in beam and cavity simulations give confidence in using $\mathrm{SC}$ cavities with numerous advantages.

\section{General Comments}

Firstly, the cost: the high RF-to-beam-power efficiency reduces the operational cost. This is a huge advantage in the case of small beam current and high energy, but becomes relatively less interesting with growing beam power. The capital cost is considered to be similar in both room-temperature and SC designs.

Flexibility: SC cavities give bigger beam aperture, but the lower associated focusing implies that the beam-tobore-aperture ratio has to be taken as the major point. The real question becomes: is there a bigger ratio using SC cavities? The answer is usually yes, questionable for space charge dominated beam. Furthermore, this discussion does not apply to particles lost longitudinally, which are lost whatever the aperture size.

Availability is commonly considered to be better in a cryogenic linac with simpler tuning, because of more stable cavities. The cooling at superconducting temperatures regulates by itself all the difficulties at room temperature observed on $\mathrm{CW}$ machines. Another availability argument in favour of SC linac is that a design tolerant to cavity faults can be obtained with a large number of resonators. In case one fails the others replace the faulty one (at least over about $10 \mathrm{MeV}$ ). At very low beta (low beam velocity) no replacements are possible, so this argument is weak.

Development of a superconducting cavity usually requires more time; the team must have expertise in a very specific field. One good point is that the young are more easily interested in high-tech structures (like the SC ones), simplifying the procurement of a team.

The severe restriction on beam losses leads to the need for accurate control of the accelerating fields. The lowlevel RF system must include both feedback and feedforward loops to maintain the amplitude and phase errors at less than $1 \%$ and $1^{\circ}$ for pulsed machine. A point in favour of SC designs compared to room temperature ones, is that the system must not allow resonant frequency tracking for heating the cavities during the turn-on procedure and/or a pulsed mode operation during beamtune up. But a pulse SC machine requires a more complicated RF system which must deal with microphonics or Lorentz detuning difficulties. All of those disturbances need a strong RF team to deal with them.

The SC cavities usually provide much higher gradients than classical room-temperature cavities, allowing a length reduction. The real estate gain starts after 100$200 \mathrm{MeV}$, so this is hardly an argument for the intermediate cavities in discussion.

\section{RT STRUCTURE CHOICE}

\section{Frequency}

For a high-power hadron machine, a frequency between 200 and $400 \mathrm{MHz}$ is ideal. As the frequency increases, the efficiency increases, the cost of the RF decreases and the shunt impedance increases, making the linac shorter and therefore the cost less (at first). The size of the structure becomes smaller, which is the objective. At some point they become too small to manufacture and/or to incorporate the different elements (focusing, pumping, 
relative manufacturing tolerances, etc.), and their cost rises. The transverse focusing becomes more difficult as one moves towards higher frequency. For example, a $400-\mathrm{MHz}$ DTL at $3 \mathrm{MeV}$ using classical electroquadrupole magnets is not possible: both SNS and J-Parc tried this approach and finally made a different choice: permanent magnet quadrupoles for SNS, and a lower frequency for J-Parc. The RF sources may become part of the choice when going down in frequency. A 1-MW CW Diacrode exists at $200 \mathrm{MHz}$ and below but there is only one manufacturer. Klystrons are preferred to tetrodes (reliable, higher gain, simpler) but they reach their lower limits at $300 \mathrm{MHz}$.

The choice is large enough to use existing possibilities from the RF tube manufacturers. Most of the time, the choice is more political or experience-based rather than supported by compelling technical reasons. RF is expensive, especially in this range of frequency; development of a new frequency is even more expensive, while one can "easily" pick up existing tubes world-wide. In Europe, there is a common frequency resulting from the LEP in CERN: $352 \mathrm{MHz}$. Almost all the European projects use a multiple of this frequency $(88,175,350$, $700 \mathrm{MHz}$ ). Some of the Asian projects use also the synergy around these frequencies while others developed the new $324 \mathrm{MHz}$ (pulse machine, J-Parc, CSNS). In US the recent choices are related to the LANSCE experience, leading to a frequency a little higher: $402.5 \mathrm{MHz}$.

\section{$R F Q$}

Ion sources commonly deliver beams in the range of 20 to $100 \mathrm{keV} / \mathrm{u}$, and then the first accelerating cavity is the RFQ. RFQs are not efficient cavities, they are expensive and have low RF/acceleration ratio. But RFQs both accelerate and bunch adiabatically to final energies as high as $\approx 7 \mathrm{MeV}$, with excellent beam quality and relatively low losses. The final energy may depend on the team's ability to manage the stabilisation of the longitudinal field in the RFQ (usually with resonant coupling plate and dipole stabilizer rods - LEDA, IFMIF, TRASCO, IPHI, PEFP, China or with the $\pi$-mode stabilizing loop - J-parc, SNS). The entrance energy should be the lowest possible compatible with the required source performances in order to minimize the RFQ length.

Different type of RFQ are in use, from the 4-rod type to the original 4-vanes type.

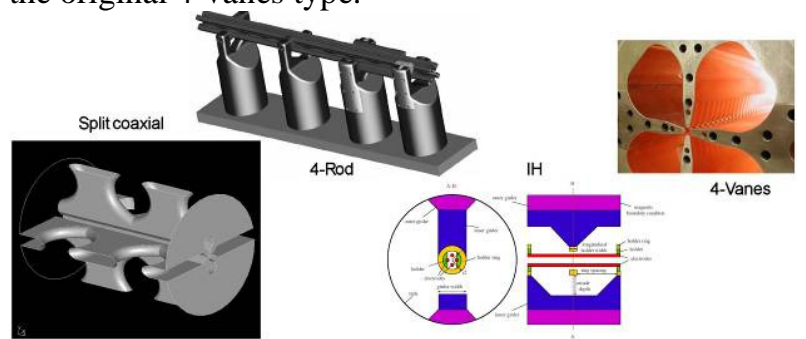

Figure 1: Various RFQ types.

The 4-rod RFQs are the simplest to build and the cheapest. The critical part is the cooling. From the power

07 Accelerator Technology Main Systems

dissipation point of view, the main difficulties are located in the base plate and stem cooling or, if used, in the tuning plates. It could lead to local field deformation and/or unfeasible cooling in high duty-cycle mode. Recently, very nice results were obtained by A. Schempp's team at a frequency of $175 \mathrm{MHz}$, which show the today feasibility limit of a CW 4-rod RFQ [6].(Figure 2).
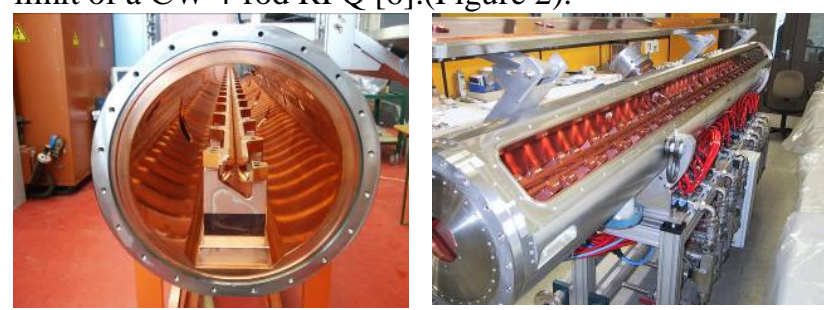

Figure 2: Left: SARAF CW RFQ - $3 \mathrm{MeV} 4 \mathrm{~mA} \mathrm{D}{ }^{+}$, $175 \mathrm{MHz}$; right: indust. 4-rod CW RFQ $176 \mathrm{MHz} / 220 \mathrm{~kW}$.

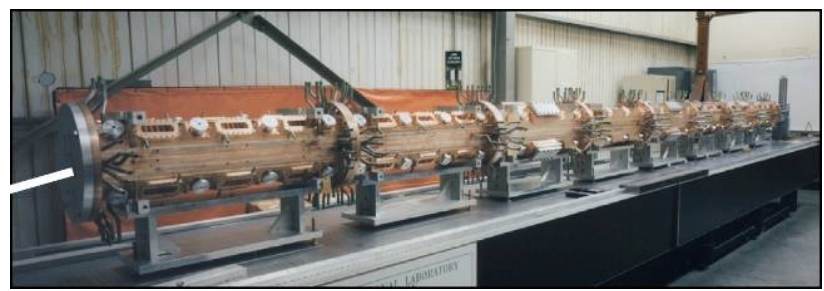

Figure 3: LEDA RFQ.

The 4-vane types RFQ are usually less RF consuming. High beam current requires high vane voltage, and the only compatible structure is a brazed RFQ 4-vane structure. This is the reference type of RFQ used for numerous high-intensity projects like TRASCO [7] (352MHz, CW, 30mA, $\left.\mathrm{p}^{+}\right)$, IPHI [8] $(352 \mathrm{MHz}, \mathrm{CW}$, $\left.100 \mathrm{~mA}, \mathrm{p}^{+}\right)$, IFMIF [9] $\left(175 \mathrm{MHz}, \mathrm{CW}, 125 \mathrm{~mA}, \mathrm{~d}^{+}\right)$, SNS $[10,11]$ (with a PILS stabilization principle, $402.5 \mathrm{MHz}$, 6\%DF, 60-38mA, H'), PEFP RFQ [12] (350MHz, $\left.24 \% \mathrm{DF}, 20 \mathrm{~mA}, \mathrm{p}^{+}\right)$. The LEDA RFQ [13] is still the world leader in terms of RFQ performances, being able to accelerate a $110-\mathrm{mA} \mathrm{CW}$ proton beam at $350 \mathrm{MHz}$ up to $6.7 \mathrm{MeV}$. The brazing process remains the most complicated part of the fabrication [14] and is required for high-power high-duty factor operation. It may become a nightmare (in Europe) or be straightforward (vertical brazing), but it is never simple. Other solutions exist like the J-parc RFQ [15] (324MHz, 3\%DF, 50mA, $\left.\mathrm{H}^{-}\right)$, which adopt laser beam welding, or bolting like SPIRAL 2 [16] for much lower frequency $(88 \mathrm{MHz})$.

Other RFQ types exist. The most interesting and promising is the pseudo-split-coaxial structure chosen for RIA/AEBL [17]. It is a cross between a 4-rod and 4-vane structure, and the adjustment of the "opening" is a good point for $\mathrm{CW}$ linacs at low frequency. It reduces the transverse size (and the cost of copper material and machining time) while allowing sufficient cooling. Nevertheless it still requires to be brazed. Other types, like the superconducting RFQ, CRFQ, etc. are not suitable in these applications.

\section{DTL, SDTL CCDTL IHDTL QWR, Spokes}

Classical room-temperature DTLs are typical for high current machines (almost all designs). Their FODO T06 Room Temperature RF 
lattice, when possible, gives the best match with RFQs and provides strong focusing for high-space-chargedominated beams (minimum transverse tune depression). They are preferred also because of an acceptable real estate $\mathrm{ZT}^{2}$ and a possible continuity of the longitudinal phase advance that give a path to current independent design. DTL recently showed that a peak field of $1.3 \mathrm{Kp}$ is very conservative [4] (1.8 $\mathrm{Kp}$ is the classically accepted value in RFQs), so room still exists for improvement.

Using room-temperature cavities, the transition energy between the RFQ and the next cavity has to take into account different parameters. If the frequency is increased, the diameter of the DTL tank diminishes. At some point it starts to be difficult, from the engineering point of view, to implement the quadrupoles inside the drift tube. Different solution can be found: amount them is the SNS choice using permanent magnet quadrupoles (PMQs) inside the first DTL tank in a FF0DD0 lattice. There are different feelings about this option: some teams fear the lack of tuning knobs (J-Parc) while others (SNS) are thankful for the reduction of tuning parameters and the associated cost reduction. PMQs allows also for a more compact drift-tube design leading to higher shunt impedance. The use of classical electromagnet quadrupoles is demonstrated at $5 \mathrm{MeV} @ 350 \mathrm{MHz} \mathrm{CW}$ (IPHI) and PMQ at $3 \mathrm{MeV}$ (SNS@400MHz 6.25\%DF).

In SDTLs (Separated-function DTLs) the drift tubes are empty leading to a much simpler and cheaper fabrication process. These were selected for ESS and J-Parc. The efficiency is better than for DTLs due to smaller drift tubes and stems. The alignment of both the cavity and the focusing elements is much easier. As there are fewer quadrupoles with lower gradient, the sensitivity to errors decreases. Correction and matching is easier. However, due to a longer transverse focusing period than for a DTL, larger bore would be necessary to reach the same beam loss criteria, which compromises the $\mathrm{ZT}^{2}$. As each tank is independent in phase and amplitude, multiple low-power rf systems, usually more expensive, must be used.

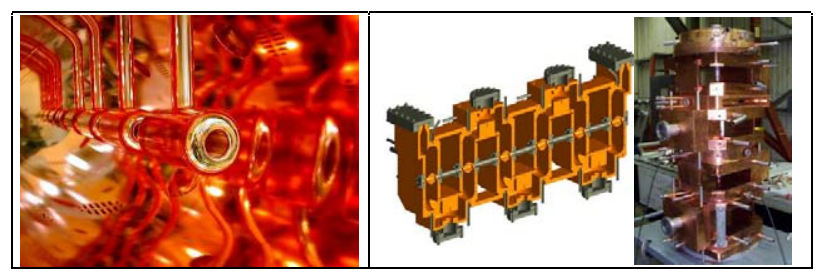

Figure 4: J-Parc SDTL and ATP CCDTL.

The CCDTL was selected in the ATP project $(110 \mathrm{~mA}$, $\mathrm{CW})$. In the present SPL, the intention is to cover the energy range from 50 to $102 \mathrm{MeV}[18,21]$. The tanks are feed by a coupling cell, and again the focusing is outside the cavity. It is known to represent a good compromise between size, maximum gradient, efficiency and focalisation. As it is a single resonator from the RF point of view, the disadvantage of many small rf sources disappears. The first thermal difficulties of such cavity type are now well established and a 2-gap cavity would be a good compromise at $700-800 \mathrm{MHz}$. The increase in shunt impedance from using three-gap cavities do not justify the extra complexity of the design [19].

There are growing interests in $\mathrm{CH}$ or IH-DTLs promoted by Frankfurt University [20]. The gain is shown on Figure 5 where the shaded areas contain the measured points for several structures in operation. The IH error bars on Figure 5 denote realized cavities with their velocity range from input to output, including the losses due to the integrated lenses. The $\mathrm{CH}$ red lines are from calculations and supported by first model measurements (GSI's p-linac design). The conventional DTLs have to be compared with the H-cavities with higher voltage gain, and lower number of element, with significant improvement on focusing lenses alignment (true also for SDTLs). This cavity type is proposed in IFMIF, EURISOL, EUROTRANS, etc.

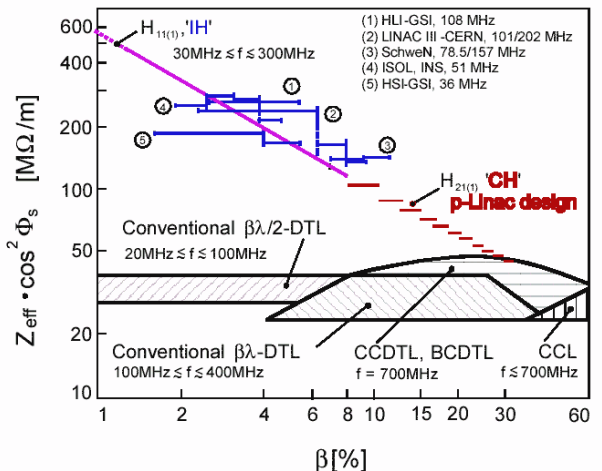

Figure 5: Comparison of shunt impedance. Abscise: square of the effective voltage gain per cavity divided by the power losses and by the (outer) tank length.

SC cavities are mostly chosen for efficiency reasons. One should also quote the original choice of SPIRAL2, using superconducting quarter-wave resonators in single cryomodules, starting at $0.75 \mathrm{MeV} / \mathrm{A}$. The main reason is related to the beam requirements: 2 to $20 \mathrm{MeV} / \mathrm{u}, \mathrm{CW}, 0$ to $5 \mathrm{~mA}, \mathrm{q} / \mathrm{A}=1$ to $\mathrm{q} / \mathrm{A}=1 / 6$. This could only be achievable using short independent cavities with high efficiency.

\section{PROJECT FEEDBACK}

\section{IFMIF}

A very representative design using room temperature is the IFMIF accelerator (International Fusion Materials Irradiation Facility), the prototyping EVEDA phase being launched. This $2 \times 125 \mathrm{~mA} \mathrm{CW} \mathrm{D}^{+}$beam at $40 \mathrm{MeV}$ will be by far the most powerful low-energy beam in the world $(2 \times 5 \mathrm{MW})$. The output beam energy requirements are 36 and $40 \mathrm{MeV}$. At the beginning of the project in 1994, even the frequency $(175 \mathrm{MHz})$ was challenging, the SC linac option was judged to be out of reach and too risky. The reference design RFQ followed by 10 DTL tanks was chosen for the sake of reliability and for the focusing scheme in accordance with the strong space charge, using standard solutions. It will still be the first CW DTL. Halo was a major concern using deuteron beam (huge activation). The choice was based on the existing recent accelerator (LEDA for APT) using a brazed 4-vane RFQ up to $5 \mathrm{MeV}$ and then a CW DTL. There is confidence that 
the objectives in cavity tolerances could be reached (roughly $\pm 50 \mu \mathrm{m}$ ).

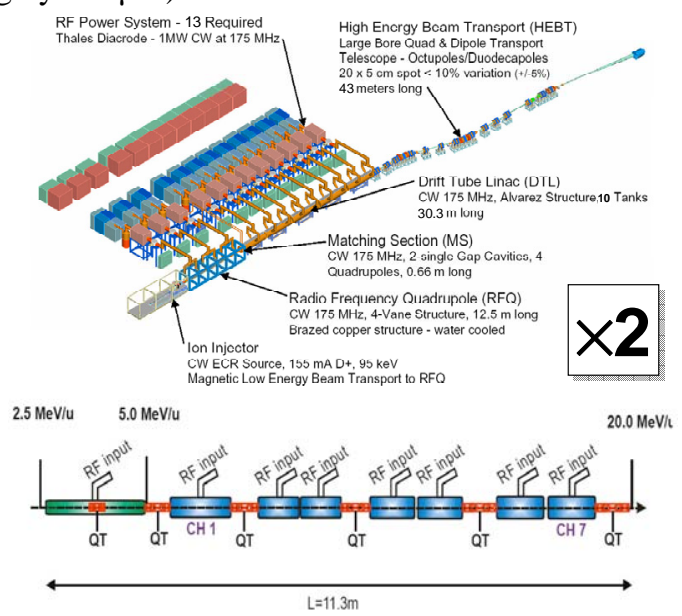

Figure 6: Schematics of the reference IFMIF accelerator and the CH-DTL optional design.

Today, a competitor design arose using a CH-DTL and followed by a series of superconducting $\mathrm{CH}$ structures. The room-temperature CH-DTL was necessary to minimize the risk associated with the unwanted particles out of the RFQ (non-accelerated, different charge-to-mass ratio, etc.). The second reason concerned the minimum beta needed for the special geometry (surface preparation, coupler room) and rf efficiency. For this option promoter, the use of single-cell SC cavities such as re-entrant or other types in the energy region of the CH-DTL would lead to very high rf-amplifier, rf-control and cryostat costs, compared to their normal conducting alternative.

\section{$S P L-L I N A C 4$}

Linac4 [21] is proposed to replace the existing proton linac at CERN (Linac2). It is expected to be the first step towards higher brightness beams in the LHC and will be the injector of the future SPL

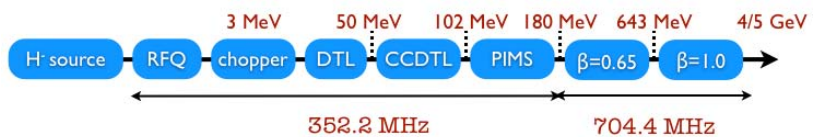

Figure 7: SPL schematic - $40 \mathrm{~mA} 5 \% \mathrm{DF}$.

The linac starts with a DTL, since the CCDTL had a too large phase advance at $3 \mathrm{MeV}$. The CCDTL has been prototyped with good results [22]. CERN main reasons to use a $\pi$-mode structure (PIMS) is the ease of fabrication and tuning, experience at CERN and the choice of a single frequency.

\section{SNS}

The SNS team at first examined proton linac designs that start with a high-energy RFQ followed by either a drift-tube linac (DTL) or a coupled-cavity drift-tube linac (CCDTL). For high energies, a conventional CCL follows the CCDTL. It was largely based on LANL team's experience with these technologies. CCDTL was later removed from the SNS design mainly to minimize the number of separate developing teams.

\section{ACKNOWLEDGEMENTS}

Many thanks to all the colleagues and friends who helped me with information and corrections. Special thanks to P. Bertrand, J-L. Biarrotte, J. Billen, J.C. Cornell, M. Ikegami, A. Facco, J. Gallambos, F. Gerigk, K. Hasegawa, J-M. Lagniel, A. Mosnier, H. Podlech, U. Ratzinger, A. Sauer, A. Schempp, D. Uriot and M. Vretenar.

\section{REFERENCES}

[1] A. Mosnier, "Survey of High-Power Proton LINACS”, LINAC2002, Korea, August 2002, p. 821827.

[2] S.O. Schriber, "Survey of proposed high intensity accelerators and their applications", EPAC94 proc. p. 213.

[3] A. Facco, "High Intensity Proton Sources", Proc. SRF 2003, 8-12 Sept, 2003, Lübeck, Germany.

[4] J.Stovall, "Low and Medium Energy Beam Acceleration in High Intensity Linacs", EPAC2004, p. 108-112.

[5] Y. Yamazaki, "Design Issues for High-Intensity, HighEnergy Proton Accelerators”, LINAC96, p. 592-596.

[6] P. Fisher, A. Schempp, "Tuning of a 4-rod CW mode RFQ accelerator”, EPAC2006, p. 1583-1585.

[7] D. Barni et al., "Status for the TRASCO Program", EPAC 2002, p. 251-253.

[8] P-Y. Beauvais, "Recent Evolutions in the Design of the French High Intensity Proton Injector (IPHI)", EPAC2004, p. 1273-1275.

[9] IFMIF Comprehensive Design Report, IFMIF team.

[10] A. Ratti et al., "Conceptual Design of the SNS RFQ", LINAC98, p. 276-278.

[11] A. Ratti et al., "The Fabrication and Initial Testing of the SNS RFQ”, PAC2001, p. 3930 - 3932.

[12] H.J. Kwon et al., "Characteristics of the PEFP $3 \mathrm{MeV}$ RFQ”, EPAC2006, p. 1334-1336.

[13]H.V. Smith et al., "LEDA Test Results and Plans", PAC2001, p. 3296-3298.

[14]D. Schrage et al., "CW RFQ Fabrication and Engineering", LINAC 1998, 679-683, 1998.

[15] Y. Kondo et al., "Fabrication and Low-Power Measurements of the J-Parc 50-mA RFQ Prototype", LINAC2006, p. 749-751

[16]R. Ferdinand et al., "SPIRAL 2 RFQ design", EPAC2004, p. 2026-2028.

[17] D. Schrage et al., "A 57-Mhz CW RFQ for the AEBL Project", J of the Korean Physical Society, Vol. 50, No. 5, May 2007, p. 1363-1367.

[18] Y. Cuvet et al., "Development of a $352 \mathrm{MhZ}$ Cellcoupled Drift Tube Linac”, LINAC04, p. 288-290.

[19]J. Billen, private conversation.

[20] Ulrich Ratzinger, private conversation.

[21]F. Gerick et al., "RF Structure for LINAC 4", this conference.

[22]M. Vretenar et al., "Design and Development of RF Structures for Linac4", LINAC06, Knoxville, USA. 